\title{
20
}

\section{Implementation of Flushing Tanks in Combined Sewer Networks to Comply with Optimal Self-Cleansing Properties}

\author{
Reza H.S.M. Shirazi, Raf Bouteligier, Patrick Willems and \\ Jean Berlamont
}

Combined sewer networks are designed to collect and transport the aqueous and solid wastes originating from domestic, industrial and catchment surfaces for treatment and disposal. One problem that arises is the sedimentation of the particles within such collected flows while in transport throughout such sewer networks. In fact, many sewer pipes in combined sewer systems experience considerable fluctuations in flows, ranging from high flow during short-term storm events to longer periods of much lower dry-weather-flows. In low flow periods sewers also experience a characteristic diurnal flow variation. In such periods when the pipe filling level is very low, minimum critical velocities might not be satisfied (Bertrand-Krajewski, 2002). Thus, deposition generally occurs during these periods and also during decelerating flows when storm runoff is receding. Although the flow of surface runoff throughout the sewer network generates considerable rates of shear stresses, this does not guarantee proper sediment transport in downstream sewer pipes due to lack of enough strength in the flow to constantly produce the required shear stresses. These possible sediment depositions can generate problems such as hydraulic overloading

Shirazi, R., R. Bouteligier, P. Willems and J. Berlamont. 2009. "Implementation of Flushing Tanks in Combined Sewer Networks to Comply with Optimal Self-Cleansing Properties." Journal of Water Management Modeling R235-20. doi: 10.14796/JWMM.R235-20.

(C) CHI 2009 www.chijournal.org ISSN: 2292-6062 (Formerly in Conceptual Modeling of Urban Water Systems. ISBN: 978-0-9808853-2-3) 
of the sewer pipes due to a reduction in flow capacity, and increase the risk of surcharging during storm events. This could also result in both surficial flooding and unwanted early operation of the combined sewer overflows (CSOs). Thus, the issue of designing sewer systems to be self-cleansing becomes important. This is however not always promising, particularly in flat regions where the necessary slopes for sewer pipes to be self-cleansing are not available (especially in the most upstream parts of the network) and due to the costs of required deep excavations and pumping stations. In this regard, a proper solution could be the use of flushing tanks that can generate controlled flushes, produced by means of the collected volumes of surface runoff flows in their tanks, into the required sections of sewer systems. The effect of such devices as external sources to help remove the settled particles from sewer pipes has been investigated by many researchers (BertrandKrajewski et al, 2005; Bouteligier et al, 2006; Campisano et al, 2004; Dettmar et al, 2002).

In this chapter an evaluation of the proper implementation of flushing tanks for eroding sediments from a combined sewer network in the village Erpe-Mere in Flanders, Belgium, is presented. The results are based on the experiments and numerical simulations carried out at the Hydraulics Laboratory of the Katholieke Universiteit Leuven (K.U.Leuven). Implementation of these flushing tanks in different locations of the sewer network is studied with regard to subsequent modifications of the hydrodynamic components of the flow throughout the network (shear stress, flow discharge, flow velocity). The research takes account of the hydraulic characteristics of the flushing wave (released flow rate as a function of time) and the specific effects on in-sewer sediment transport. The methodology consists of using version 7.5 of InfoWorks CS (Wallingford Software, UK) in order to calculate the resulting spatially distributed shear stresses as a function of the pipe diameters and slopes to evaluate eroding capabilities of the generated flush waves in the sewer network. Emphasis is given to verifying whether the simulated shear stresses throughout the network reasonably satisfy the required self-cleansing conditions, i.e. the generated shear stresses remain high enough for a small time interval. Of particular concern is the proper location of multiple flushing devices all over the combined sewer network with respect to the potential degree of sediment removal and transport, and the possible drawbacks which could occur during such flushing events, such as modification of the flow cross section and consequent effects on sewer surcharging or flooding. In fact, there are 
various influencing parameters related to the proper installation of these devices such as sewer network characteristics, contributing catchment characteristics, etc. The evaluation results indicate that attaining a minimum shear stress criterion (e.g. $3 \mathrm{~N} / \mathrm{m}^{2}$ for combined sewer networks based on the Flemish sewer design requirements) could not be satisfied in all parts of the considered sewer network and even some undesired effects emerged. Nevertheless, regarding the accomplished modeling analyses, the capability of such devices to produce effective forces for removal of the settled particles from combined sewer networks is well accounted for.

\subsection{Methodology}

\subsubsection{InfoWorks Modeling}

Validated mathematical models are becoming necessary simulation tools for evaluating compliance with progressively more strict environmental standards for receiving water courses. These modeling tools can be applied to quantitatively assess the performance of different water quality management options (Ashley et al, 1998). The field of urban drainage design has lately benefited from the availability of sewer flow quality modeling tools in addition to the hydrodynamic simulation packages which would lead to an enhanced design and management of urban drainage systems. Thus, together with general hydraulic results generated by hydrodynamic modeling, the ability to properly model the impact of sediment accumulation in sewer systems as well as the amount of sediments and pollutants that are transported into receiving waters or treatment plants has become possible. In this study, version 7.5 of InfoWorks CS, which is a modeling tool for simulating urban drainage systems, was utilized. The water quality simulation module within the InfoWorks package by default utilizes the Ackers (1991) relationship for sediment transport modeling.

For the required sediment transport modeling in this study, the model for the sewer network of Erpe-Mere (case-study) was chosen which had the following characteristics: 289 contributing subcatchments, 368 manholes of which nine were outfalls, 358 conduits, ten fixed weirs, six pumps, seven flap valves, one hydraulic control, and finally the cumulative length of sewer pipes being $29101 \mathrm{~m}$. The studied sewer network is shown in Figure 20.1. 


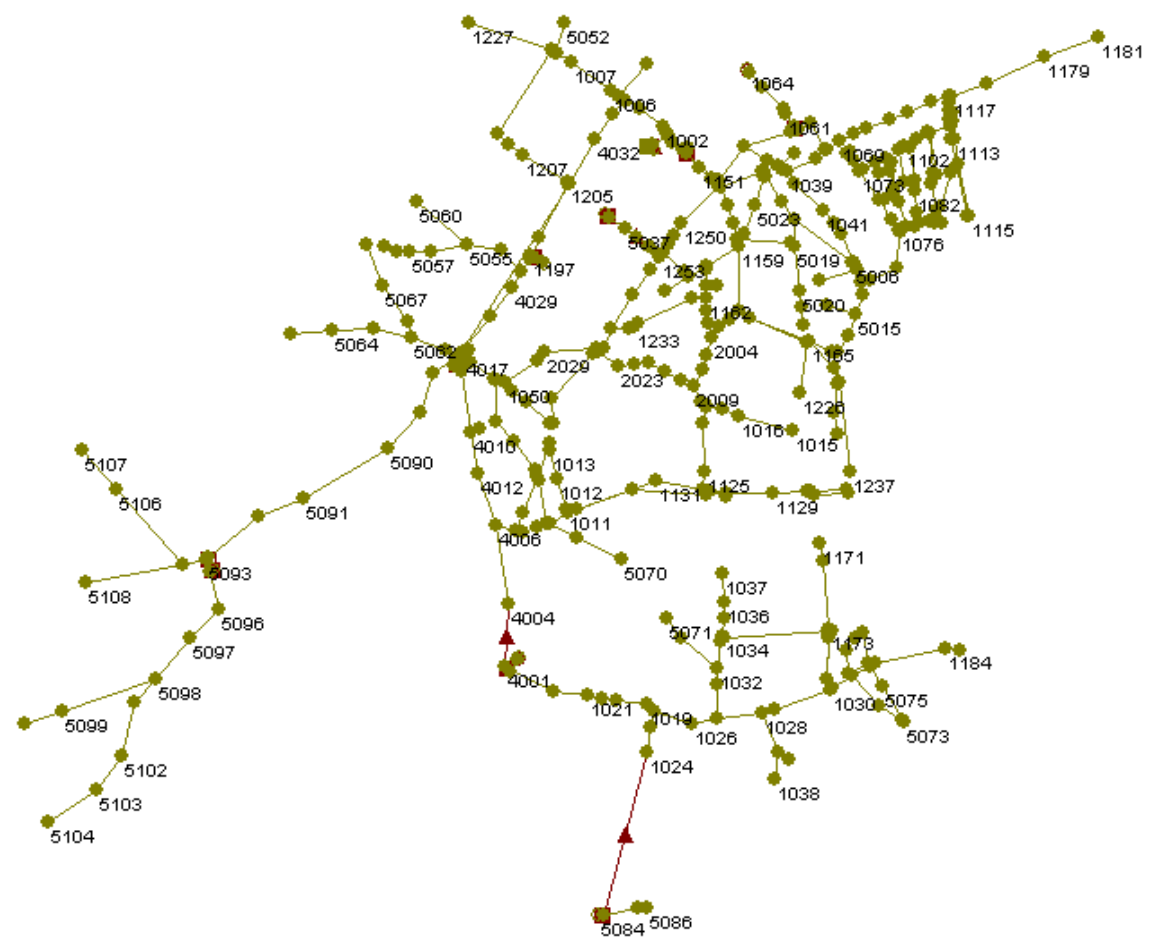

Figure 20.1 The sewer network of Erpe-Mere in Flanders, Belgium.

\subsubsection{Characteristics of the Flushing Tank}

\section{Description of the flushing device}

The flushing device (provided by Keramo-Steinzeug, Belgium) which will be evaluated in this chapter comprises a tank of $1 \mathrm{~m}$ height, with a diameter of $1.2 \mathrm{~m}$ and a volume of about $0.45 \mathrm{~m}^{3}$, releasing a flushing discharge in between 27 and $19 \mathrm{~L} / \mathrm{s}$ that lasts for at least 20 seconds. Surface runoff can reach the flushing device by means of a connection to the side wall of the tank. In rainy periods the water level in the tank rises until the water height exceeds a given level and then the excess flow is bypassed, and, by means of a certain hydraulic process within the tank, the stored water flows through the outfall of the device and initiates a flush wave into the connected pipe. The flushing device is illustrated in figure 20.2. 


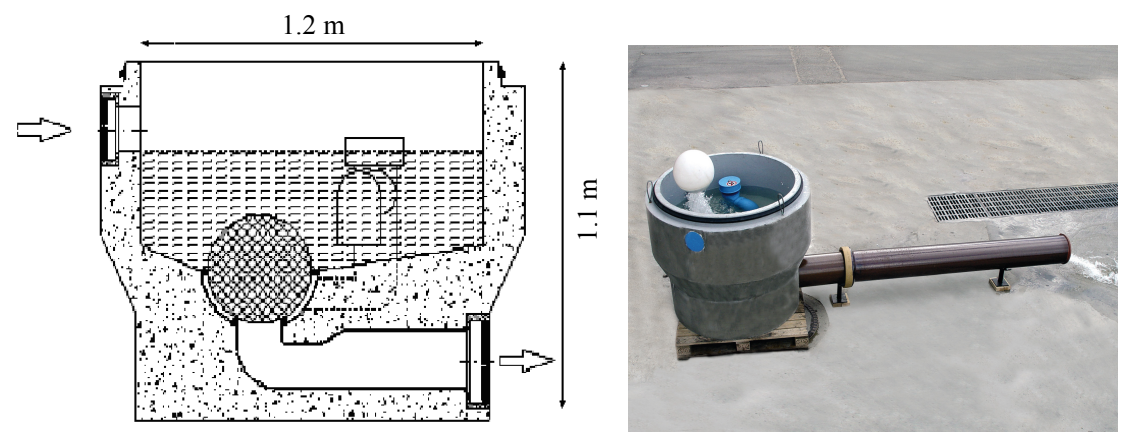

Figure 20.2 Illustrations of the flushing tank.

\section{Hydraulic Characteristics of the Flushing Wave}

The flushing tank is evaluated in this research regarding its capabilities for generating the required shear stresses throughout the connected sewer pipes, by the effect of the flush waves (outflow discharges) released in each flushing session. In fact, there is a variation in the outflow discharge while the flush occurs, which is due to the reduction in the initial water level in the tank and the consequent energy loss of the outflow. Hence, based on the Bernoulli's equation, head loss computations and the geometrical characteristics of the flushing device, the outflow hydrograph from the flushing tank is obtained (Bouteligier et al., 2006) as shown in figure 20.3.

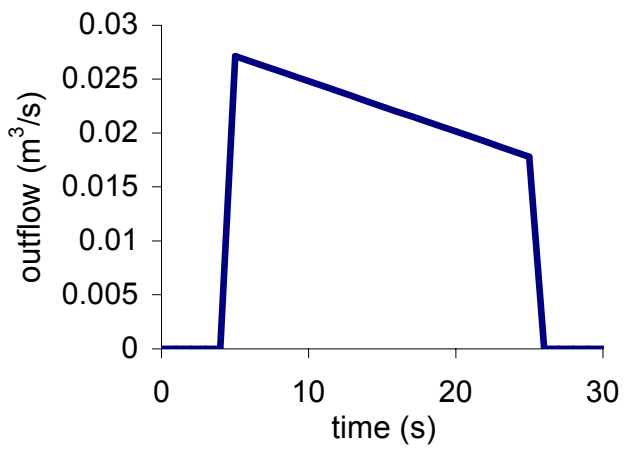

Figure 20.3 The outflow hydrograph for one flushing cycle. 


\subsubsection{Shear Stress Calculations}

Hydraulically speaking, there are various methods for shear stress estimations and other hydraulic components of the flow in sewer networks. By performing a water quality simulation in InfoWorks CS, shear stresses are automatically generated and the following formula is implemented for such calculations (the shear stress is calculated as a function of the water head, the hydraulic radius and the (friction) slope of the flow):

$$
\tau=\frac{\lambda_{c}}{8} \rho \cdot v^{2}
$$

where:

$$
\begin{aligned}
\tau & =\text { the shear stress }\left[\mathrm{N} / \mathrm{m}^{2}\right], \\
\lambda_{c} & =\text { the composite friction factor }[-], \\
\rho & =\text { the water density }\left[\mathrm{kg} / \mathrm{m}^{3}\right], \text { and } \\
v & =\text { the flow velocity }[\mathrm{m} / \mathrm{s}] .
\end{aligned}
$$

Besides, the uniform velocity is computed according to the following formula in which $R$ is the hydraulic radius [m], and $S_{0}$ is the pipe bottom slope $[\mathrm{m} / \mathrm{m}]$ :

$$
v=\sqrt{\frac{8 g}{\lambda_{c}}} \cdot \sqrt{R S_{0}}
$$

\subsubsection{The Self-Cleansing Conditions}

Sewers should be designed to transport sediment at a rate sufficient to limit the depth of deposition to a specified proportion of the pipe diameter, to maintain the required hydraulic characteristics of the conduit. In order to evaluate the self-cleansing conditions in a sewer pipe often a velocity or a shear stress criterion is used (e.g. Ashley et al., 2004; Dettmar and Staufer, 2005). Traditionally, a simplified representation of particle displacement has been proposed: deposition of a solid takes place when either flow depth or mean velocity fall below a critical value, and re-entrainment takes place when that critical value is subsequently exceeded (Davies et al., 1996). Later it was found that this criterion (minimum self-cleansing velocity) specific to sediment characteristics or other hydraulic features of sewer networks could not appropriately characterize the ability of sewer flows to transport sediments. In fact, a more appropriate measure for evaluating the self-cleansing capability 
of the flow would be analysing the acquired values of shear stresses along the sewer pipes considering the hydrodynamic and sediment characteristics of the network. It is important to note that the shear stress (as a tractive force) is the key parameter for the start of sediment erosion when its critical value for a certain sediment is exceeded. The magnitude of erosion varies in response to the time varying hydraulics. In fact, temporal and local fluctuations of the flow conditions which cause turbulence are responsible for sediment movement. The amount of entrained particles at any time depends on the instantaneous turbulent shear stress initiated by the velocity fluctuations and the instantaneous shear stresses at the bed (Keshavarzy \& Ball, 1999). At first, single particles are discarded and then complete lumps of deposits are transported with the current when the forces exceed the bed deposit tolerance. Along with sufficient flow velocity or bottom shear stress, successive occurrence of flow conditions which would force deposited particles to unhinge has a substantial effect on the resuspension of the settled particles.

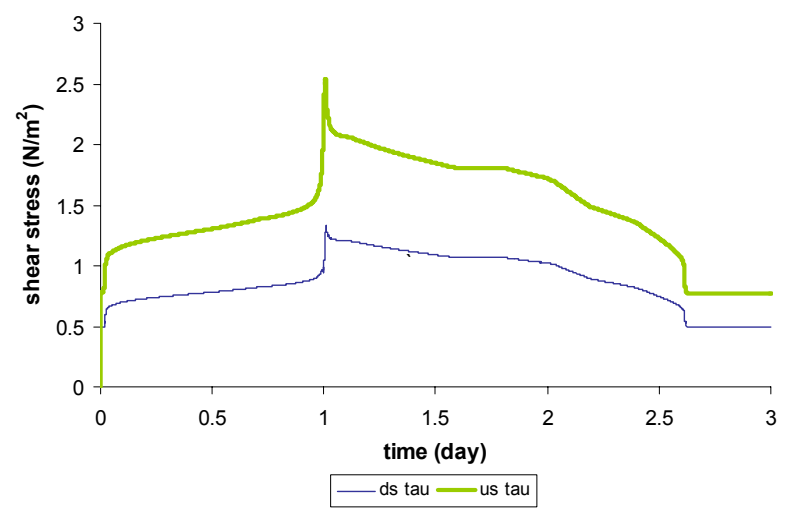

Figure 20.4 Upstream (us) and downstream (ds) shear stresses (tau) for pipe 5089.1 in the network.

Here, for evaluating the proper implementation of flushing tanks in sewer networks, it was firstly required to consider relevant shear stress limits for sediment transport. As in Flanders a minimum shear stress of $3 \mathrm{~N} / \mathrm{m}^{2}$ is required for combined sewer pipes to be self-cleansing (Vaes et al., 2004), this value was set as the required limit. Judgment on the necessity for flush tank utilization for certain parts of the sewer network was based on analysing both the upstream and downstream shear stress results. Only shear stress values that maintained at least for a duration of 10 seconds above the 
self-cleansing limit were assumed to be effective, otherwise they were disregarded. An example of simulated shear stress results less than the selfcleansing conditions is illustrated in Figure 20.4.

\subsubsection{Numerical Oscillations}

Prior to using any sewer flow quality modeling tool, it is of significant importance to understand the modeling algorithm, the way it represents the processes that occur in the sewer system, as well as the influencing parameters. It was understood that the simulation parameters could play a very important role on the accuracy of the simulation results. In fact, by implementing the default simulation parameters in the InfoWorks CS software, there appeared to be instabilities in the obtained results in the form of spikes and numerical oscillation. Numerical instabilities appeared only for certain pipes in the network. Thus, it was imperative to modify these parameters in a way to improve the results in order to increase the stability and reliability of the obtained simulated shear stress values. However, it was likely that by modifying the simulation parameters, due to the effect of the numerical diffusion, the shape of the resulted shear stress graphs would also alter, and this would certainly affect the assessments on proper implementation of the flushing devices. So, modifying the default simulation parameters in the modeling process, although they could improve the numerical instabilities in the simulation results, was avoided and the spikes were eliminated by means of manual averaging. An example of numerical spikes in the results is illustrated in Figure 20.5.

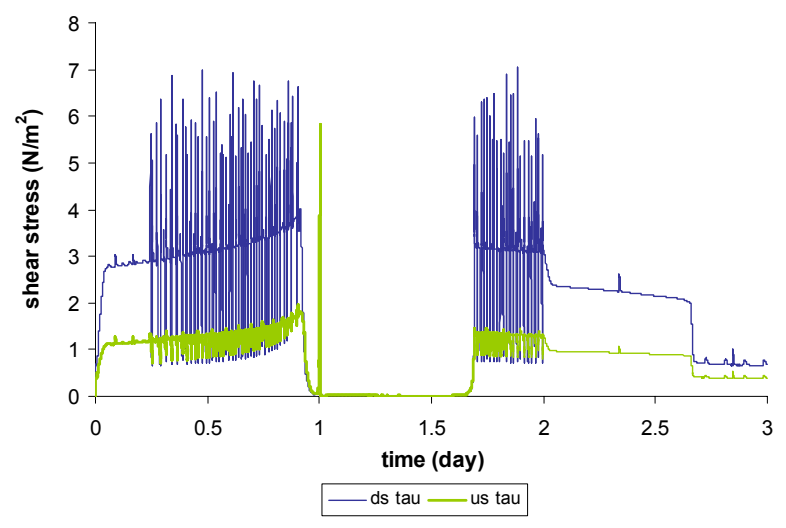

Figure 20.5 Numerical spikes in the upstream (us) and downstream (ds) shear stress results for pipe 2015.1 in the network. 


\subsubsection{Multiple Flushing Tanks in the Sewer Network}

As discussed before, it is important to implement flushing devices in proper locations of a sewer network to generate the required shear stresses where the existing hydraulic situation does not satisfy the self-cleansing conditions. Initially it is essential that the flow direction through the whole sewer network be distinguished. For proper definition of flow directions through the network, loops need to be identified. Moreover, the most suitable places for flush tanks would be the sections upstream of the pipes in which the existing shear stresses are less than the required limits. The attempt to locate such spots requires that the reference hydraulic conditions generated by catchment runoff in the sewer network be studied and the deficiencies in the self-cleansing shear stresses (as described above) be assessed.

For doing so, a composite rainfall storm (Vaes \& Berlamont, 1999) with a frequency of one per year was chosen to be implemented in the model, and by running the simulation engine within the software the hydrodynamic characteristics of the network were simulated. Then, several pipes that realised shear stresses lower than the required limits were distinguished. Afterwards, a number of flushing devices for those critical locations were implemented and the generated shear stresses were compared with the reference condition. As many as 61 flush tanks were installed by a trial-anderror procedure in order to solve the deficiency of self-cleansing forces in the network. The installations were made at proper locations in the network and with respect to the possible impacts over the network hydraulic characteristics and proper functioning of other available hydraulic structures. Adding more flushing devices where there was no improvement in the hydraulic characteristics of the sewer network was avoided. An economic analysis to compare the cost-benefit ratio of implementing flush tanks in the considered network could be useful in refining the selection, although was not done in this study.

\subsection{Results and Discussion}

\subsubsection{Considering the Effects of Pipe Characteristics on Flush Waves}

As a general prospect regarding urban drainage design, sewers need to be designed and built to avoid sedimentation (minimum slopes, smooth material, small angles for connections and rounded shapes) (BertrandKrajewski, 2002). It is known that the propensity for sediment deposition 
will be different depending upon the location of a sewer in the network, i.e. the relative type of flow input and the physical characteristics of the conduit such as size, shape, and gradient would influence sedimentation processes (Fraser \& Ashley, 1999). In fact, as the generated outflow discharge of each flush is about $20 \mathrm{~L} / \mathrm{s}$, the characteristics of receiving pipes (especially pipe diameter and bottom slope) could be important when evaluating the influence of such flush waves through the downstream pipes, i.e. there would be a notable difference in the generated flush characteristics in the connected pipes with various diameters and slopes. Also, the pipe length is an important parameter regarding the flush characteristics when it is propagating through the network. If the lengths of the pipes are too long, flushing might not be effective.

\subsubsection{The Effect of Network Characteristics on Produced Shear Stresses}

The presence of structural and hydraulic discontinuities in a sewer system (loops, geometry of pipes, special structures, etc.) also determines the location of in-sewer deposits (Camuffo et al., 2002). Thus, in the process of implementing flushing tanks in a sewer network, the network characteristics should be taken into account. These include the contributing catchment characteristics (rainfall characteristics, catchment land-use type, availability of subcatchment surface runoff for the manholes where flush tanks are planned to be located), the configuration of the sewer pipes within the network (availability of loops, angles between successive conduits and at the connections), and the availability of controls in the network (flap valves, pumps, weirs, etc.). The influences of these parameters on the flow propagation throughout a sewer network are described as follows:

- The subcatchment characteristics affect the runoff generated by the storm and should be considered. The practical way for flushing the manholes where no subcatchment surface runoff is available is to install the flush tank in the closest possible location upstream of such manholes.

- The angle between any two successive sewer pipes downstream of the flush tank affects the generated flush waves through those pipes (loss in the flow head), especially due to the fact that generated flushes have turbulent characteristics and this would even intensify the 
effect of the connection angle. In fact, when choosing the location of the manholes where flush tanks would be located, the negative effects of the flush waves on the flow in the downstream sewer pipes should be prevented.

- Loop systems also influence the flush propagation through the network by reducing the velocity and turbulence characteristics. So, in parts of the network with looped connections there would be complications in the flow path and this should be considered when implementing flush tanks for such areas of the network.

- Control facilities in the network and the way they function should be considered when installing flushing tanks in sewer networks. Special controls (flap valves, pumps, weirs, siphons) would affect the downstream sections, as these may disturb the flow by creating obstructions and thus raising the hydraulic grade line, slowing down flow rates, and producing turbulence. Locations upstream of these controls (in their vicinity) should be avoided when installing flush tanks in the network.

Thus, in selecting flushing tanks for a sewer network all the mentioned parameters should be considered, and their combined effects on the simultaneous performance of numerous flush tanks in the network need to be properly evaluated. Besides, the influence of flush tanks on the functioning of existing controls in the network should be assessed and any negative impacts (regarding their initial designed purposes) should be avoided.

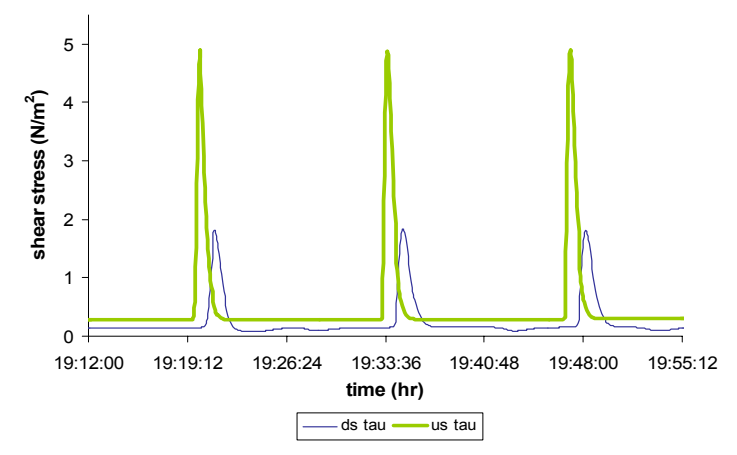

Figure 20.6 Deficiency in generated downstream (ds) shear stresses even after flush tanks were installed in the network for pipe 1278.1. 
As an example illustrating the restrictions in the efficiency of flush tanks in the considered sewer network, Figure 20.6 shows the deficiency in the generated shear stresses even after flush tanks were located upstream of a certain pipe. In fact, due to the lack of available subcatchment surface runoff for the upstream manholes close to the pipe the flush tanks were located at a considerable distance from the pipe and thus such distant flushing could not generate the required self-cleansing forces in the considered sewer pipe.

\subsubsection{Combined Effects of Numerous Flushing Tanks}

Extreme rainfall storms, inaccurate design and insufficient maintenance are the main causes of surcharge of sewer pipes or flooding of urban drainage systems. Flushing devices, when employed in already constructed sewer networks, are considered as external maintenance tools for which there were no considerations during the design phase. It is certain that these devices would have some undesirable impacts on the hydraulic characteristics of the network. Thus, when implementing these devices their effect on surcharging of conduits and flooding of manholes should be assessed. One potential drawback could be the flooding of the manhole where the flush tank is located, as it is possible that the flushing device cannot cope with the surface runoff volume (due to the limitation of its outflow capacity) when there is a heavy storm in the catchment and thus the flooding of the manhole happens. Also, for sewers with small diameters, backwater effects could occur, resulting from the influence of flush waves on the carrying capacity of downstream sewers due to the extra volume of water flowing abruptly into a certain point in the network in each flushing cycle. In this regard, proper evaluations could be done by analysing the water surface profile to investigate the impact of the flush on the flow depth and other hydrodynamic properties of the network. An example of the effect of flush tanks on downstream hydraulic characteristics is illustrated in Figure 20.7. Note that the increase in downstream shears stresses is solely due to the effects of flush waves.

Table 20.1 Results after the 1st attempt of implementation of flush tanks in the network.

\begin{tabular}{cccccc}
\hline $\begin{array}{c}\text { Total number } \\
\text { of pipes } \\
358\end{array}$ & $\begin{array}{c}\text { Pipes } \\
\text { require } \\
\text { flushing }\end{array}$ & $\begin{array}{c}\text { Number of } \\
\text { implemented } \\
\text { flush tanks } \\
\text { (1st attempt) }\end{array}$ & $\begin{array}{c}\text { Pipes with } \\
\text { satisfied } \\
\text { self-cleansing }\end{array}$ & $\begin{array}{c}\text { Pipes without } \\
\text { satisfied } \\
\text { self-cleansing }\end{array}$ & $\begin{array}{c}\text { Number of } \\
\text { pipes with } \\
\text { improvements } \\
\text { in results }\end{array}$ \\
\hline & 94 & 61 & 44 & 50 & 15 \\
\% of total & 26 & 17 & 47 & 53 & 16 \\
\hline
\end{tabular}




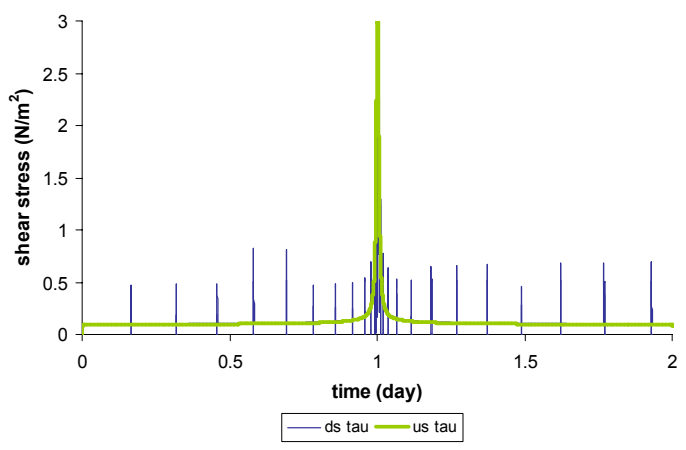

Figure 20.7 The effect of flush tanks on modification of upstream (us) and downstream (ds) shear stresses in pipe 5065.1.

The results regarding the evaluation of self-cleansing conditions in the studied network after the first attempt of implementing the flush tanks (performed hydrodynamic simulations) is presented in Table 20.1.

In summary, the results indicate that the considered self-cleansing conditions (based on the Flemish regulations) could not be satisfied in all parts of the studied sewer network. Nevertheless, some improvements from the existing situation to the required criteria have been achieved, and thus it can be stated that the capability of such flush tanks to produce effective selfcleansing forces in most parts of the studied network is well accounted for. An example illustrating the improvement in the generated shear stresses in pipe 1185.1 is shown in Figure 20.8 (a) and 20.8 (b):

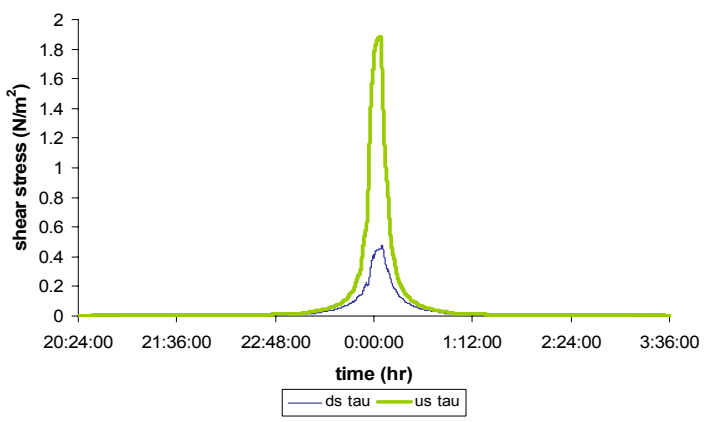

Figure 20.8 (a) Upstream (us) and downstream (ds) shear stress before implementing flush tank. 


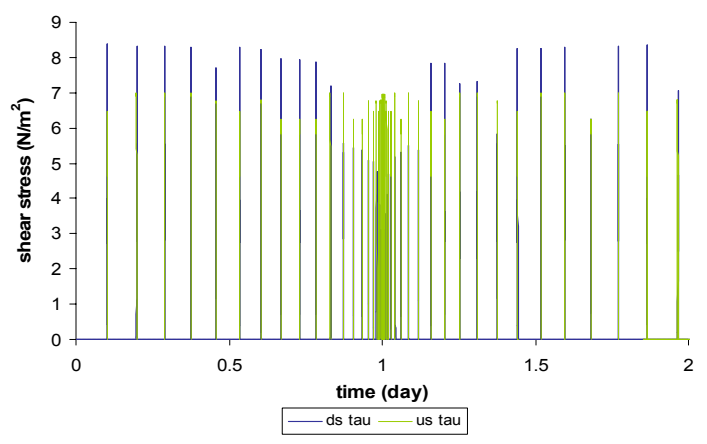

Figure 20.8 (b) Upstream (us) and downstream (ds) shear stress after implementing flush tank.

\subsection{Conclusions}

In this chapter an evaluation of the proper implementation of a flushing tank for eroding sediments from the combined sewer network in the village ErpeMere in Flanders, Belgium is presented which is based on the experiments and numerical simulations carried out at the Hydraulics Laboratory of the Katholieke Universiteit Leuven. The research focused on the hydraulic characteristics of the flushing tank, and evaluated the eroding capabilities of the generated flush waves using the InfoWorks CS model (Wallingford Software, UK). Appropriate implementation of these flushing tanks in different locations of the sewer network was studied with respect to the potential degree of sediment removal and transport, and the possible drawbacks which could occur such as sewer surcharging or flooding. Selfcleansing conditions were assumed to be fulfilled when generated shear stresses lasted for a minimum duration of $10 \mathrm{sec}$ higher than $3 \mathrm{~N} / \mathrm{m}^{2}$, so that the effect on sediment transport would be sufficient.

The characteristics of the existing sewer pipes (diameter, bottom slope, conduit length and location) were found to be important in choosing proper installation spots for flushing tanks in the network. In this regard, network characteristics should also be accounted for, which include catchment characteristics (rainfall characteristics, land-use type for the connected catchment area, availability of subcatchment surface runoff for the manholes where flush tanks are supposed to be located), configuration of sewer pipes within the network (availability of loops, angles between successive conduits and in the connections), and presence of controls in the network 
(flap valves, pumps, weirs, etc.). Combined effects of the mentioned characteristics on the performance of numerous flush tanks in the network should also be considered. Besides, the influence of flush tanks on the function of existing controls in the network needs to be assessed and any negative impacts (regarding their initial designed purposes) should be avoided. The relation between the lack of prevailing shear stresses and the hydraulic characteristics of the network (subcatchment characteristics, diameter and slope of the pipes, etc.) could be important when deciding to add extra flush tanks. Besides, due to economical constraints the number of flushing devices to be implemented in a sewer network should be limited (to the lowest possible number) in accordance with the existing size and characteristics of the network.

As the first attempt, as many as 61 flush tanks were applied in the modeling procedure in the required locations in the studied sewer network, which resulted in $47 \%$ improvements in generating the required selfcleansing shear stresses. The results indicate that self-cleansing conditions could not be satisfied in all parts of the considered sewer network, and would reflect the fact that such flushing tanks cannot necessarily provide widespread sought benefits regarding sewer network cleansing. Nevertheless, the overall capability of such devices to produce effective forces for sediment removal in sewer networks is well accounted for and thus their application could be a proper means for maintenance implementations regarding urban drainage system management in the future.

\section{Acknowledgments}

The authors are grateful to Keramo-Steinzeug to have given the opportunity to the Hydraulics Laboratory of the Katholieke Universiteit Leuven to carry out the experiments on the flushing tank. The authors would also like to express their appreciation to Wallingford Software for providing the essential software tool InfoWorks CS.

\section{References}

Ashley R.M., Bertrand-Krajewski J.-L., Hvitved-Jacobsen T. and Verbanck M. (2004). Solids in Sewers: Characteristics, Effects and Control of Sewer Solids and Associated Pollutants. Scientific and Technical Report No. 14. Joint Committee on Urban Drainage, Sewer Systems and Processes Working Group, IWA Publishing, London, United Kingdom. May 2004. ISBN: 1900222914. 
Bertrand-Krajewski J.-L., Bardin J.-P. and Gibello C. (2005). Long Term Monitoring of Sewer Sediment Accumulation and Flushing Experiments in a Man-Entry Sewer. Proc of the 10th International Conference on Urban Drainage, Copenhagen, Denmark. 21-26 August 2005.

Bertrand-Krajewski J-L (2002). Sewer Sediment Management: Some Historical Aspects of Egg-Shape Sewers and Flushing Tanks. Proc of the 3rd International Conference on Sewer Processes and Networks, Paris, France. 15-17 April 2002.

Bouteligier R., Shirazi R.H.S.M. and Berlamont J. (2006). Evaluation of the Cleansing Capacity of a Flushing Tank in (Sanitary) Sewer Systems. Proc of the 7th International Conference on Urban Drainage Modelling and the 4th International Conference on Water Sensitive Urban Design, Melbourne, Australia. 2-7 April 2006.

Bouteligier R., Vaes G. and Berlamont J. (2002). Transport Models for Combined Sewer Systems. Research project commissioned by Aquafin NV and Severn Trent Water Ltd., Hydraulics Laboratory, Katholieke Universiteit Leuven, Leuven, Belgium.

Bouteligier R., Vaes G., Berlamont J., Flamink C., Langeveld J.G. and Clemens F.H.L.R. (2005). Advection-Dispersion Modelling Tools: What about Numerical Dispersion? Water Science and Technology, 52 (3), 19-27.

Campisano A., Creaco E., Modica C. and Ragusa F. (2004). Laboratory Experiments on Bed Deposit Scouring during Flushing Operations. Proc of the 4th International Conference on Sewer Processes and Networks, Funchal, Madeira, Portugal. 22-24 November 2004.

Camuffo G., Tait S. and Marion A. (2002). Erosion of Organic Sediment Deposits Formed under Different Environmental Conditions. Proc of the 3rd International Conference on Sewer Processes and Networks, Paris, France. 15-17 April 2002.

Dettmar J., Rietsch B. and Lorenz U. (2002). Performance and Operation of Flushing Devices - Results of a Field and Laboratory Study. Proc of the 9th International Conference on Urban Drainage, Portland, Oregon, USA. 8-13 September 2002.

Dettmar J. and Staufer P. (2004). Modelling of Flushing Waves for Optimising Cleaning Operations. Proc of the 6th International Conference on Urban Drainage Modelling, Dresden, Germany. 15-17 September 2004.

Dettmar J. and Staufer P. (2005). Behaviour of the Activated Storage-Volume of Flushing Waves on Cleaning Performance. Proc of the 10th International Conference on Urban Drainage, Copenhagen, Denmark, 21-26 August 2005.

Gerard C. and Chocat B. (1998). An Aid for the Diagnosis of Sewerage Networks: Analysis and Modelling of the Links between Networks' Physical Structure and the Risk of Sediment Build-up. Proc of the 4th International Conference on Developments in Urban Drainage Modelling, London, UK. 21-24 September 1998.

Keshavarzy A. and Ball J.E. (1999). Initiation of Sediment Motion at the Bed with Turbulent Shear Stresses in an Open Channel Flow. Proc of the 8th International Conference on Urban Storm Drainage, Sydney, Australia. 30 August - 3 September 1999.

McIlhatton T.D., Ashley Richard and Tait S. (2004). Improved Formulations for Rapid Erosion of Diverse Solids in Combined Sewers. Proc of the 6th International Conference on Urban Drainage Modelling, Dresden, Germany. 15-17 September 2004. 
Vaes G. and Berlamont J. (1999). The Influence of Rainfall and Model Simplification on Combined Sewer System Design. Hydraulics Laboratory, Katholieke Universiteit Leuven, Leuven, Belgium.

Vaes G., Bouteligier R., Luyckx G., Willems P. and Berlamont J. (2004). Explanation of the Guidelines for the Design of Sewer Systems (in Dutch). For the Administration of Environment, Nature, Land and Water Management AMINAL (Ministry of Flanders, Department of Environment \& Infrastructure), Hydraulics Laboratory, Katholieke Universiteit Leuven, Leuven, Belgium.

Wallingford Software (2007). InfoWorks CS Help, Wallingford Software Ltd., United Kingdom. 
